\title{
The Effect of Protein and Glycemic Index on Children's Body Composition: The DiOGenes Randomized Study
}

AUTHORS: Angeliki Papadaki, PhD, ${ }^{a}$ Manolis Linardakis, MSc, ${ }^{\text {a }}$ Thomas M. Larsen, PhD, ${ }^{b}$ Marleen A. van Baak,

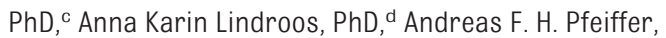
MD, e,f J. Alfredo Martinez, PhD, 8 Teodora HandjievaDarlenska, MD, PhD, h Marie Kunesová, MD, PhD, ' Claus Holst, MSci, PhD, ${ }^{j}$ Arne Astrup, MD, DSc, ${ }^{b}$ Wim H. M. Saris, MD, PhD, ${ }^{\mathrm{c}}$ and Anthony Kafatos, MD, a on behalf of the DiOGenes Study Group

${ }^{a}$ Department of Social Medicine, Preventive Medicine and Nutrition Clinic, University of Crete, Heraklion, Crete, Greece; ${ }^{b}$ Department of Human Nutrition, Faculty of Life Sciences, University of Copenhagen, Copenhagen, Denmark; ' Department of Human Biology, Nutrition and Toxicology Research Institute Maastricht, University of Maastricht, Maastricht, Netherlands; aMR Human Nutrition Research, Elsie Widdowson Laboratory,

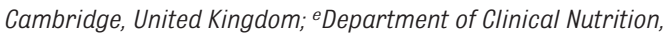
German Institute of Human Nutrition Potsdam-Rehbruecke, Nuthetal, Germany; ${ }^{\text {fDepartment }}$ of Endocrinology, Diabetes and Nutrition, Charité Universitätsmedizin Berlin, Berlin, Germany; ${ }^{g}$ Department of Physiology and Nutrition, University of Navarra, Pamplona, Spain; hDepartment of Human Nutrition, Dietetics and Metabolic Diseases, National Transport Hospital, Sofia, Bulgaria; 'Obesity Management Centre, Institute of Endocrinology, Prague, Czech Republic; and Institute of Preventive Medicine, Center for Health and Society, Copenhagen, Denmark

KEY WORDS

childhood adiposity, dietary intervention, DiOGenes, glycemic index, protein, randomized controlled trial

\section{ABBREVIATIONS}

HP-high protein

Gl-glycemic index

LGl-low glycemic index

$\mathrm{HGl}$-high glycemic index

DiOGenes-Diet, Obesity, and Genes

LCD-low-calorie diet

LP-low protein

This trial has been registered at www.clinicaltrials.gov (identifier NCT00390637)

www.pediatrics.org/cgi/doi/10.1542/peds.2009-3633

doi:10.1542/peds.2009-3633

Accepted for publication Jul 16, 2010

Address correspondence to Angeliki Papadaki, PhD, Preventive Medicine and Nutrition Clinic, Department of Social Medicine, Faculty of Medicine, University of Crete, Greece, P0 Box 2208, Heraklion 710 03, Crete, Greece. E-mail: agpapadak@edu.med. uoc.gr

PEDIATRICS (ISSN Numbers: Print, 0031-4005; Online, 1098-4275).

Copyright (@) 2010 by the American Academy of Pediatrics

FINANCIAL DISCLOSURE: The authors have indicated they have no financial relationships relevant to this article to disclose.
WHAT'S KNOWN ON THIS SUBJECT: The potential of HP and LGI diets to promote weight loss in adults has resulted in research to investigate the effect of these diets on weight control in children; results have been promising but still conflicting.

WHAT THIS STUDY ADDS: In the DiOGenes study, a European family-based, randomized, controlled, multicenter, 6-month energy ad libitum dietary intervention study, the LP/HGI diet increased body fat, whereas overweight/obesity decreased in those on the HP/LGI diet.

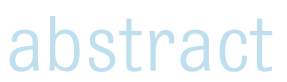

OBJECTIVE: To investigate the effect of protein and glycemic index (Gl) on body composition among European children in the randomized, 6-month dietary intervention Di0Genes (diet, obesity, and genes) family-based study.

PATIENTS AND METHODS: In the study, 827 children (381 boys and 446 girls), aged 5 to 18 years, completed baseline examinations. Families with parents who lost $\geq 8 \%$ of their weight during an 8-week run-in low-calorie diet period were randomly assigned to 1 of 5 ad libitum diets: low protein (LP)/low ǵlycemic index (LGI); LP/high Gl (HGI); high protein (HP)/LGl; HP/HGl; and control diet. The target difference was 15 GI U between the $\mathrm{LGI} / \mathrm{HGl}$ groups and 13 protein percentage points between the LP/HP groups. There were 658 children examined after 4 weeks. Advice on food-choice modification was provided at 6 visits during this period. No advice on weight loss was provided because the focus of the study was the ability of the diets to affect outcomes through appetite regulation. Anthropometric measurements and body composition were assessed at baseline, week 4, and week 26.

RESULTS: In the study, 465 children (58.1\%) completed all assessments. The achieved differences between the $\mathrm{Gl}$ and protein groups were $2.3 \mathrm{GI} \mathrm{U}$ and 4.9 protein percentage points, respectively. The LP/ HGl group increased body fat percentage significantly more than the other groups ( $P=.040$; partial $\eta^{2}=0.039$ ), and the percentage of overweight/obese children in the HP/LGl group decreased significantly during the intervention $(P=.031)$.

CONCLUSIONS: Neither GI nor protein had an isolated effect on body composition. However, the LP/HGl combination increased body fat, whereas the HP/LGl combination was protective against obesity in this sample of children. Pediatrics 2010;126:e1143-e1152 
Adiposity in childhood is associated with increased risk of mortality. ${ }^{1-5} \mathrm{Re}-$ cent increases in energy intake, produced by untoward changes in macronutrient composition ${ }^{4,6}$ and factors such as portion size, availability and cost of food and soft drinks, and reduction in physical activity, have reportedly played a major role in the rise of obesity. 4,7 With high-protein (HP) diets, weight loss is promoted ${ }^{8}$ and weight regain in adults is prevented, ${ }^{9}$ most probably by increasing satiety. ${ }^{10} \mathrm{How}$ ever, this has not been indicated in obese children. ${ }^{11,12}$ Low-glycemic index (LGl) diets are also suggested to promote weight loss in adults, mainly by promoting satiety and reducing hunger. ${ }^{13,14}$ However, the clinical usefulness of $\mathrm{Gl}$ in weight regulation has been questioned. ${ }^{15}$ In children, LGI meals compared with HGI meals significantly reduced subsequent energy intake and hunger in some, ${ }^{13,16}$ but not all, ${ }^{17}$ studies.

The effect of HP, LGI diets in children has not been assessed in large-scale, randomized controlled studies. We aimed to investigate the effect of protein and $\mathrm{Gl}$ on body weight, anthropometric measurements, and body composition among free-living children after a 6-month, family-based dietary intervention. It should be noted that no advice on weight loss was provided to children because the intervention gave less emphasis on energy intake (which was ad libitum), but focused on the ability of the diets to regulate appetite and thus body weight and composition. This study is part of the European integrated project DiOGenes (Diet, Obesity, and Genes), which focused on dietary means of preventing weight gain ${ }^{9,18,19}$ and was performed in 8 European centers.

\section{PATIENTS AND METHODS}

\section{Participants}

Volunteer families from 8 countries (Netherlands, Denmark, United King- dom, Greece, Germany, Spain, Bulgaria, and Czech Republic) were invited to participate during the period from November 2005 to April 2007. Families attended a screening examination to determine eligibility. Eligible families were generally healthy, with at least 1 parent overweight (BMI $\geq 27 \mathrm{~kg} / \mathrm{m}^{2}$ ) and younger than 65 years, and at least 1 child between the age of 5 and 18 years. ${ }^{9}$ Recruitment strategies and exclusion criteria for parents are provided in detail elsewhere. ${ }^{9}$ Exclusion criteria for children were special diets, food intolerances, systemic infections/chronic diseases, use of medication that might influence study outcomes, and drug or alcohol abuse. Informed consent was obtained from parents and assent was obtained from the children, according to local legislation. The study was approved by the local medical ethical committees in the respective countries.

\section{Study Design and Procedures}

A description of the design and study procedures are provided in an earlier report. ${ }^{9}$ In short, eligible adults underwent an 8-week low-calorie diet (LCD) period after their screening, during which the enrolled children received no intervention. During the seventh week of the LCD, children attended a clinical examination (representing baseline), ${ }^{9}$ when anthropometric pa- rameters and body composition were assessed and a 3-day weighed dietary record was provided. Families with at least 1 parent who lost $\geq 8 \%$ of weight during the LCD were randomly assigned to 1 of 5 ad libitum diets: Iow protein (LP)/LGl; LP/HGl; HP/LGl; HP/HGl; and control diet (national dietary guidelines, with medium protein content and no specific instructions on Gl). ${ }^{19}$ Eligible families were allocated to a dietary intervention group by using a simple block randomization procedure with stratification. ${ }^{9}$

Randomization was followed by (1) in Maastricht and Copenhagen, a 6-month supermarket period (free food provided to families by laboratory shops, in addition to dietary instructions), ${ }^{20,21}$ and (2) in remaining centers, a 6-month dietary instructiononly period. Families followed their randomized diet for 6 months. Children attended a second clinical examination 4 weeks into their randomized diet (same measurements as baseline, apart from body composition) and a final examination at the end of the 6-month intervention (week 26, same measurements as baseline) (Fig 1).

\section{Dietary Instruction Period}

On the day families were randomly assigned, trained dietitians gave detailed 
instructions on the ad libitum diets. All diets were low in fat $(25 \%-30 \%$ of energy). The target was for protein content to comprise $10 \%$ to $15 \%$ of energy intake in the LP and $23 \%$ to $28 \%$ in the HP groups, complying with the acceptable range $(10 \%-30 \%)$ for children aged 4 to 18 years. ${ }^{22}$ Children in the LGI groups were advised to consume the LGI foods, and those in the $\mathrm{HGl}$ groups to consume the $\mathrm{HGl}$ foods within a food group. ${ }^{19}$ The aim was to achieve a 15-point Gl difference between the $\mathrm{HGl}$ and LGl groups. The assignment of $\mathrm{Gl}$ values to foods is reported separately. ${ }^{23}$

Children were encouraged to be present during the randomization visit; otherwise, parents were instructed to aid their children with their randomized diets. During the intervention, children were requested to attend 6 counseling sessions, accompanied by their parents, during which intensive guidance was provided. Dietitians advised on weight control and reinforced the diet composition messages ${ }^{19}$ through food-choice and behavior-modification advice. A detailed description of the diets is provided elsewhere. ${ }^{19}$

\section{Anthropometric Measurements}

Standard operating procedures were produced for all investigations undertaken to ensure standardization across the centers. Moreover, the same measurement devices were used in each center on every occasion a measurement was provided. ${ }^{9}$ Subjects had been fasting for 4 hours before the clinical examinations, and they were measured in their underwear and with an empty bladder.

Weight was measured on calibrated digital scales (Seca 861, Hamburg, Germany) to the nearest $0.1 \mathrm{~kg}$, and height was measured to the nearest millimeter with a wall-mounted stadiometer (Seca 225, Hamburg, Germany), without shoes, on all examinations and di- etary counseling sessions. BMI was calculated as weight divided by height, squared $\left(\mathrm{kg} / \mathrm{m}^{2}\right)$, and weight status was determined according to the ageand gender-specific International Obesity Task Force iso-BMI $\geq 25 \mathrm{lim}$ its. ${ }^{24}$ Waist circumference (measured midway between the lower rib and iliac crest) and hip circumference (measured at the widest point between the hips and buttocks) circumference were measured twice, to the nearest $0.5 \mathrm{~cm}$, with a tape in a vertical plane and with the subject standing and gently breathing out. The mean of the 2 measurements was recorded. Waist-to-hip ratio was then calculated. ${ }^{9}$

\section{Body Composition}

Body composition was determined by dual-energy radiograph absorption (Lunar Radiation, Madison, WI) or bioelectric impedance analysis (QuadScan 4000; Bodystat, Douglas, Isle of Man, United Kingdom). Children who participated in the determination of body composition were fasting (no intake of foods or liquids for at least 4 hours before the investigations except for a water intake of $350-500 \mathrm{~mL}$ ). ${ }^{9}$

\section{Dietary Records}

All families were provided with weighing scales (Soehnle 1208 Actuell Backnang, Germany) and were instructed to record their food and liquid intake for 3 consecutive days (2 weekdays and 1 weekend day). Participants were required to weigh all foods and beverages consumed, as well as leftovers, and to provide cooking methods and recipes for composite meals. When weighing was not possible, participants were instructed to record their intake in household measures. Parents were instructed to aid their children with the recording process when appropriate. Dietary records were checked for completeness on return to clarify any uncertainties. The method of analysis of dietary records is reported elsewhere. ${ }^{9,23}$

\section{Statistical Analysis}

Primary outcome measures were changes in anthropometric measurements, BMI z score, and body composition during the intervention. Secondary outcomes were changes in the proportion of overweight and obese children and changes in waist-to-hip circumference ratio. Baseline characteristics of participants were compared between the different countries by using the Kruskal Wallis rank test and Pearson's $\chi^{2}$ test. Changes in dietary intakes during the intervention were calculated for those participants who provided food diaries at baseline, week 4 , and week 26 , and comparisons between dietary groups were performed by using the Kruskal Wallis test. Comparisons of overall changes in anthropometric measurements during the dietary intervention between dietary groups were performed by using analysis of covariance, with age, gender, family structure (single parent, couple with 1 randomized, and couple with both randomized), and country as covariates. These analyses were performed for "completers only" (all randomized subjects with data from all clinical examinations), as well as on an "intention-to-treat" basis, by using the multiple imputation technique for all randomly assigned subjects. ${ }^{25,26}$ For the completers' analysis, the observed power effect size was $72 \%$. In addition, the differences in effect between the protein groups and the Gl groups and potential interaction between $\mathrm{Gl}$ and protein content were analyzed by analysis of covariance (same covariates as above). A McNemar test was used to examine changes in weight status (overweight and obese children) within the dietary groups. All analyses were performed by using SPSS 17.0 (SPSS Inc, Chicago, 
IL), and significance was defined as $P<.05$.

\section{RESULTS}

A total of 1140 children were registered to attend screening, and 827 attended the baseline examination. Eight hundred children were randomly assigned, and 465 (201 boys, 264 girls) attended all clinical examinations (baseline, week 4, and week 26) and were included in present analyses. In total, 335 children ( $41.9 \%$ of those randomly assigned) dropped out or were excluded during the dietary intervention because of their parents' withdrawal, noncompliance with study requirements, or because they did not attend at least 1 of the above mentioned clinical examinations (completers only) (Fig 2). Baseline characteristics did not differ between completers and children who did not provide information at all visits or dropped out (data not shown).

Baseline characteristics of children who completed the intervention at the 8 different centers are shown in Table 1. Children differed in various variables between the different centers. There were no baseline differences in anthropometric measurements between the 5 dietary groups (completers' analysis).

Only 113 children $(24.3 \%$ of those who attended all clinical examinations) recorded their dietary intake at all 3 time points. At all time points, self-reported dietary protein content had increased significantly in the HP groups, resulting in a 4.9-percentage point difference between the HP and LP groups at week $26(P<.001)$ (Table 2). Between baseline and 26 weeks, the proportion of energy from carbohydrates was reduced more in the HP group than in the LP group ( -2.6 vs $4.8 \%$; $P<.001)$. Gl was reduced in the $2 \mathrm{LGl}$ groups at week 26, resulting in a 2-point difference between the LGI and HGI groups

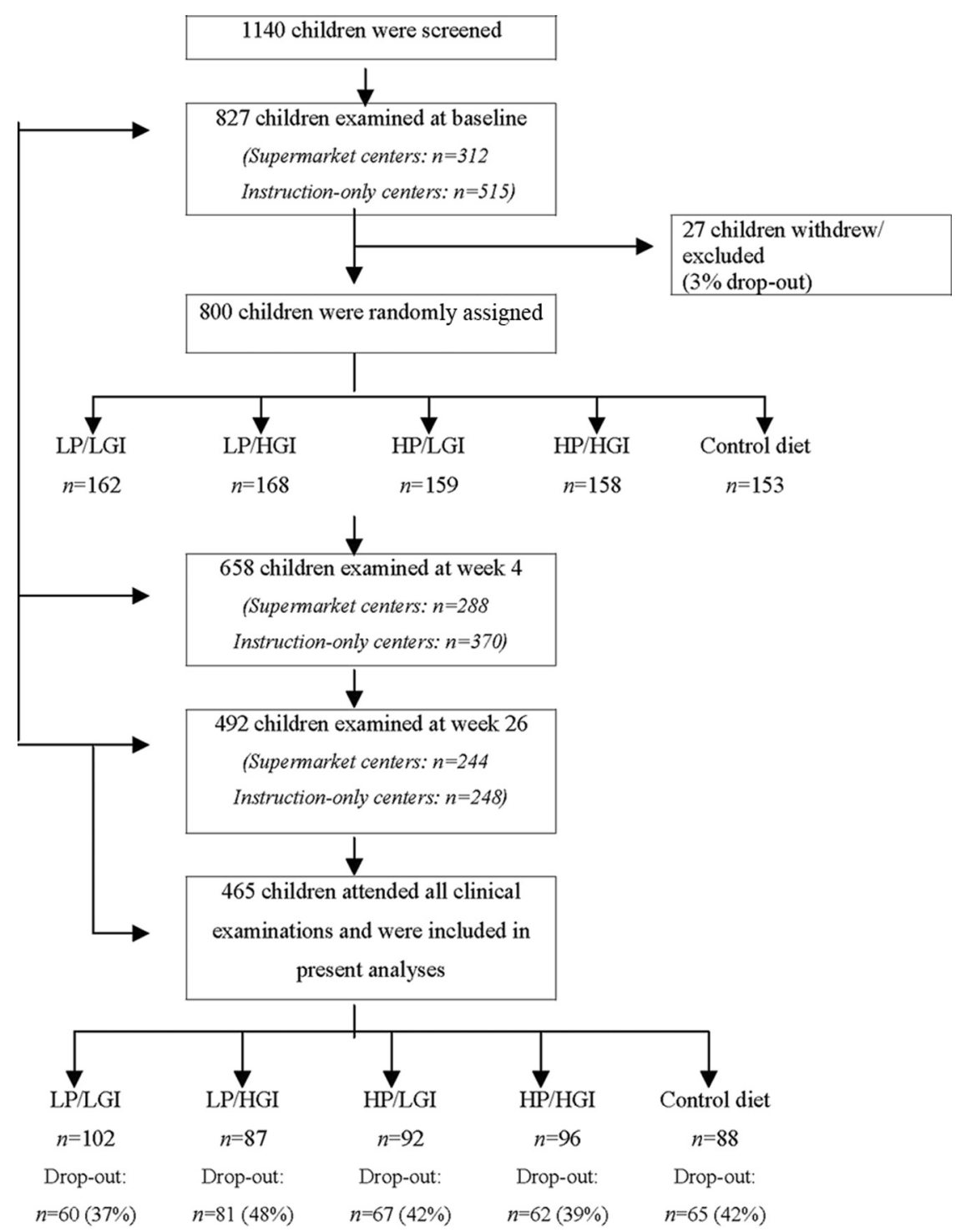

FIGURE 2

Flow diagram in which the progress of the participants from screening to the end of intervention is shown.

$(P=.013)$. Glycemic load was, as expected, reduced more in the HP group than in the LP group during the intervention $(-37.9$ vs $-12.8 \mathrm{~g} /$ day; $P=$ .006). The proportion of energy from fat did not differ among groups and was within the recommended levels of $25 \%$ to $30 \%$ at 4 and 26 weeks.

Between baseline and 26 weeks, there was a significant increase among the overall sample (completers) in body weight (53.2 vs $54.4 \mathrm{~kg} ; P<.001$ ), height (1.53 vs $1.55 \mathrm{~m} ; P<.001$ ), hip circumference ( 85.5 vs $85.9 \mathrm{~cm} ; P=$
.041 ), and fat-free mass (37.7 vs 39.0 kg; $P<.001$ ), whereas waist-to-hip ratio ( 0.855 vs $0.846 ; P<.001)$ and waistto-height ratio (0.477 vs $0.467 ; P<$ $.001)$ were significantly reduced. No statistically significant differences in changes in outcome measures among the dietary groups were observed during the intervention, apart from a statistically significant increase in body fat percentage in the $\mathrm{LP} / \mathrm{HGl}$ group $(P$ $=.040$; partial $\eta^{2}=0.039$ ) and a statistically significant reduction in the percentage of overweight/obese chil- 


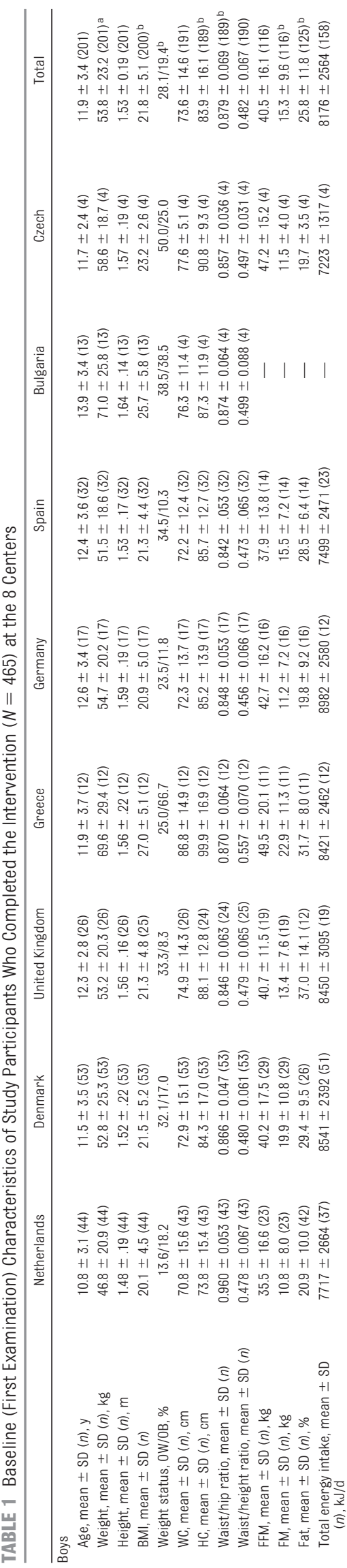

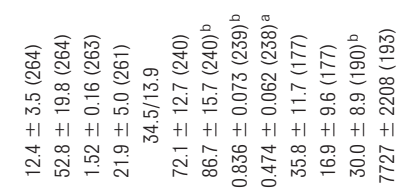

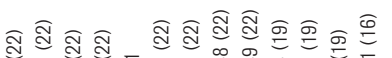

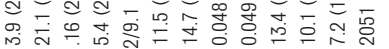

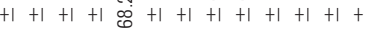

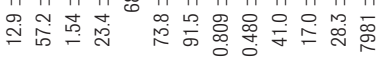

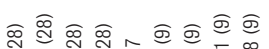

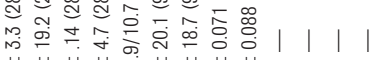

$+1+1+1+1 \underset{2}{2}+1+1+1+1$

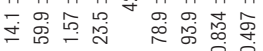

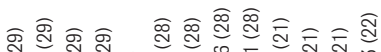

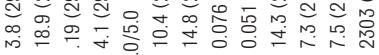
$+1+1+1+1 \int^{5}+1+1+1+1+1+1+1+1$

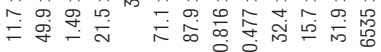

ఏ을

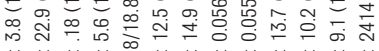

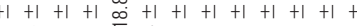

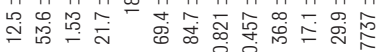

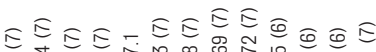

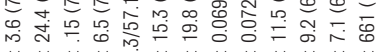
$+1+1+1+1 \geq \pm+1+1+1+1+1+1+1+1$

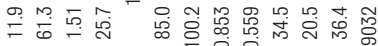

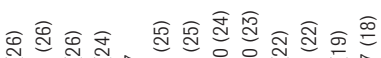

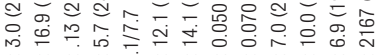
$+1+1+1+1,5+1+1+1+1+1+1+1+1$

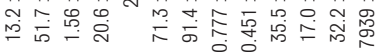

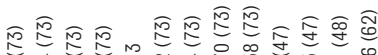

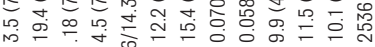

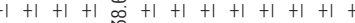

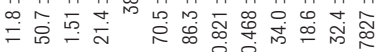

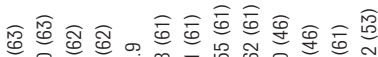

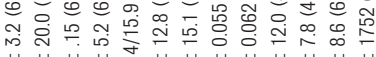

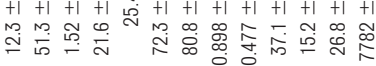

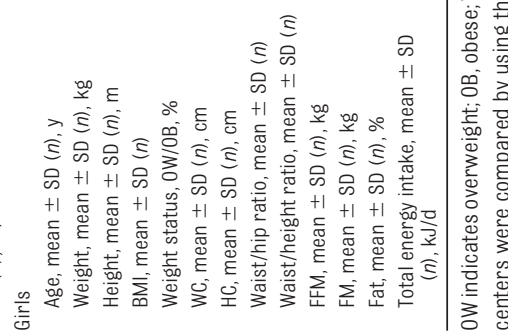

dren in the HP/LGl group (Table 3; Figs 3 and 4). When the main effect of protein and $\mathrm{Gl}$ and the interaction between protein and GI were assessed, no significant changes in outcome measures were observed between the groups. Multiple imputation confirmed that the LP/HGl group had the highest increase in body fat percentage: imputation number $4(P=.034)$ and imputation number $5(P=.013)$.

\section{DISCUSSION}

Excess adiposity is said to be the most serious health problem that affects children in developed countries. ${ }^{4}$ The potential of $\mathrm{HP}^{8}$ and $\mathrm{LGl}^{14}$ diets to promote weight loss in adults has resulted in research that investigates the effect of these diets on weight control in children, with promising but still conflicting results. The DiOGenes study has several strengths compared with earlier studies because it involved a prospective large-scale, randomized controlled design. With the intervention we examined the effectiveness of the diet (application in a real-life setting), and the family-based plan encouraged support between family members that could positively affect treatment in children. ${ }^{4,9}$

Our most significant finding, that the combination of LP and $\mathrm{HGl}$ increased body fat percentage, may suggest that this dietary combination does not affect body composition favorably. LP diets hinder satiety and energy expenditure and inhibit fat oxidation by increasing insulin response. ${ }^{10}$ In addition, carbohydrates with $\mathrm{HGl}$ are rapidly digested, thereby increasing insulin levels, stimulating hunger, and promoting food intake and the accumulation of body fat. 14,27-29 These mechanisms may explain the increase in body fat observed in the LP/HGI group. In contrast, the percentage of overweight/obese children in the HP/LGI group decreased significantly during 
TABLE 2 Mean Changes in Self-reported Total Energy and Macronutrient Intake, Gl, and Glycemic Load in the 5 Dietary Groups, for Children Who Provided Dietary Records at Baseline, Week 4 and Week 26

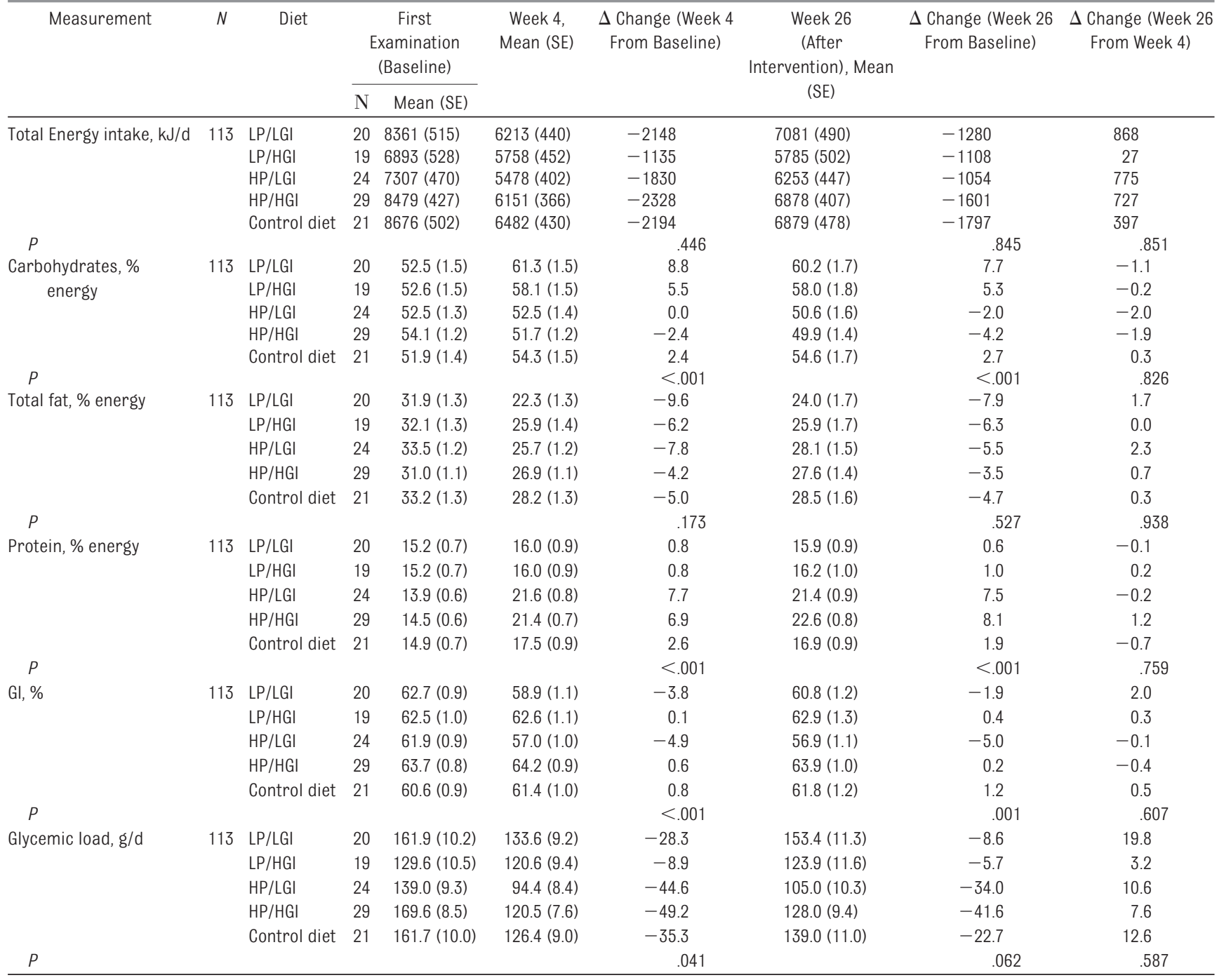

Comparisons of overall changes between dietary groups were performed by using the Kruskal-Wallis rank test.

the intervention, which is in line with the purported beneficial impact of HP and LGI diets on satiety, weight loss, and fat oxidation.8,10,13,14 Considering the lack of isolated effect of protein and $\mathrm{Gl}$ in the present study, it might be that the combination of protein and $\mathrm{Gl}$ is a more important factor that affects insulin response and thus also hunger and fat accumulation.

Bioelectric impedance analysis has been suggested to generally underestimate body fat in comparison with dual-energy x-ray absorption. ${ }^{30}$ However, the 2 methods were not used interchangeably in this study. Thus, each child was measured by using the same method each time body composition was determined. In addition, although there are some differences in outcome between the 2 methods, the main interest of our study was the $\Delta$-change in body composition. Although body fat percentage measurements were only available for 262 participants, there were no differences in age, gender, baseline BMI, or dietary group between those who provided this measurement and those who did not.

Advice on dietary protein (LP versus HP) did not influence body weight and other anthropometric measurements in this sample of European children. However, the HP group's protein intake comprised $\sim 20 \%$ of energy, which was lower than the $23 \%$ to $28 \%$ recommended in this group. The LP group's protein intake comprised $\sim 16 \%$ of energy at week 26 , slightly above the recommended $10 \%$ to $15 \%$. Consistent with 2 earlier reports in which the effect of HP compared with normal-protein diets, on body weight, and body composition in obese children and adolescents were examined, the lack of protein effect in our study might have been the result of the HP groups not reaching their recommended protein intake levels and the subsequent smaller- 
TABLE 3 Mean Changes of Outcome Measures Over the 6-Month Dietary Intervention Period

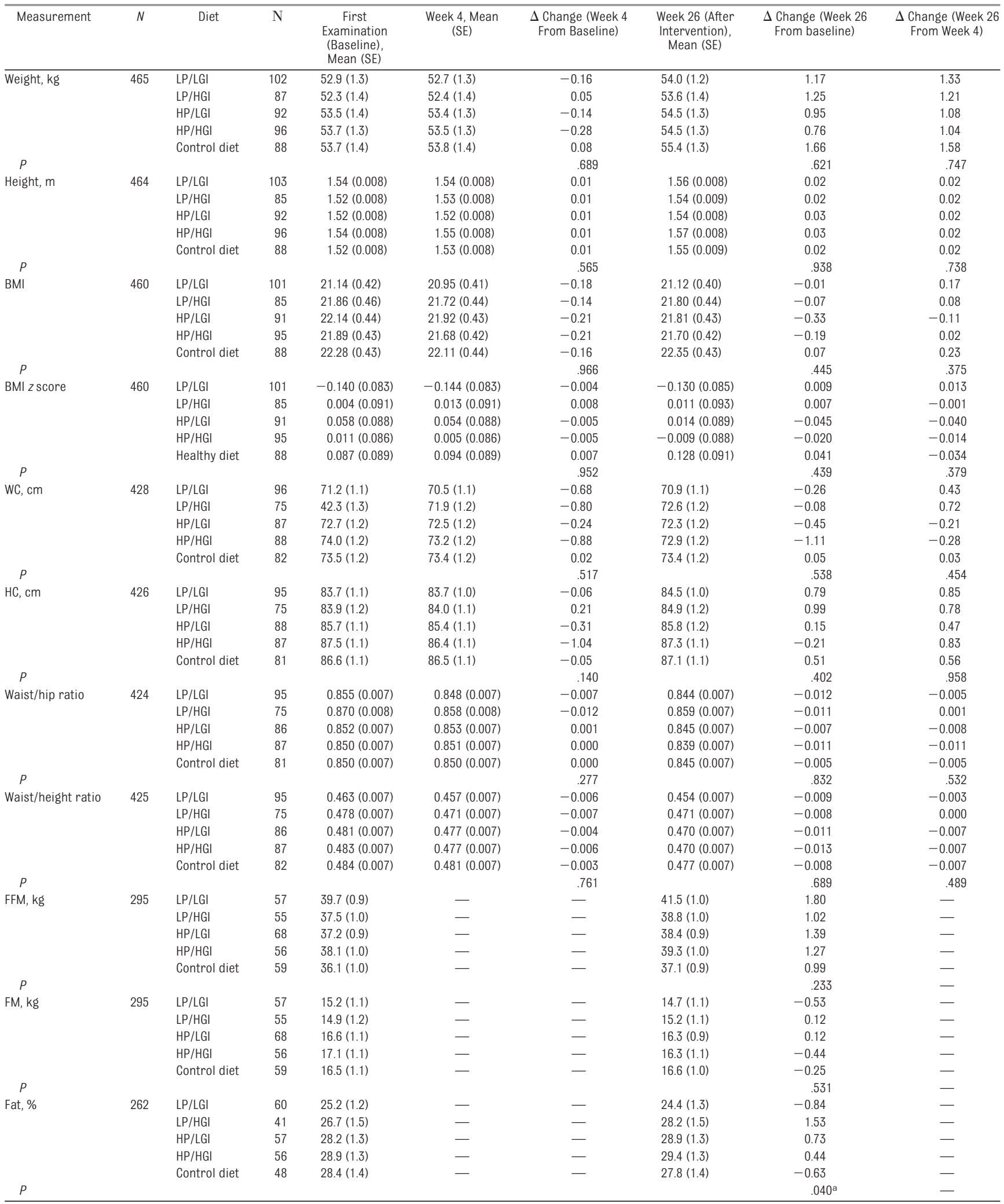

Comparisons of overall changes between dietary groups were performed by using analysis of covariance, with age, gender, family structure, and country as covariates. Effect-size estimates for analysis of covariance were determined with partial $\eta^{2}\left(\eta^{2}=0.01\right.$ is a small effect size, 0.06 is a medium effect size, and 0.14 is large effect size). WC indicates waist circumference; HC, hip circumference; FFM, fat free mass; FM, fat mass.

a Partial $\eta^{2}=0.039$ 


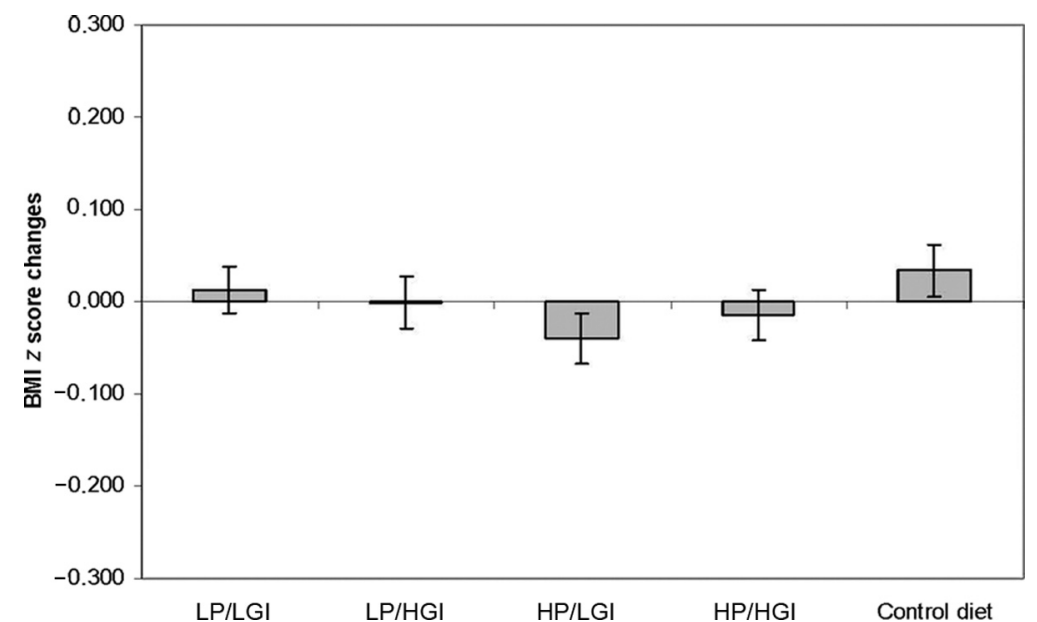

FIGURE 3

Mean changes in BMI z scores over the 6-month dietary intervention. Bars indicate SE. Levels of significance were assessed by using analysis of covariance (age, gender, family structure, and country as covariates).

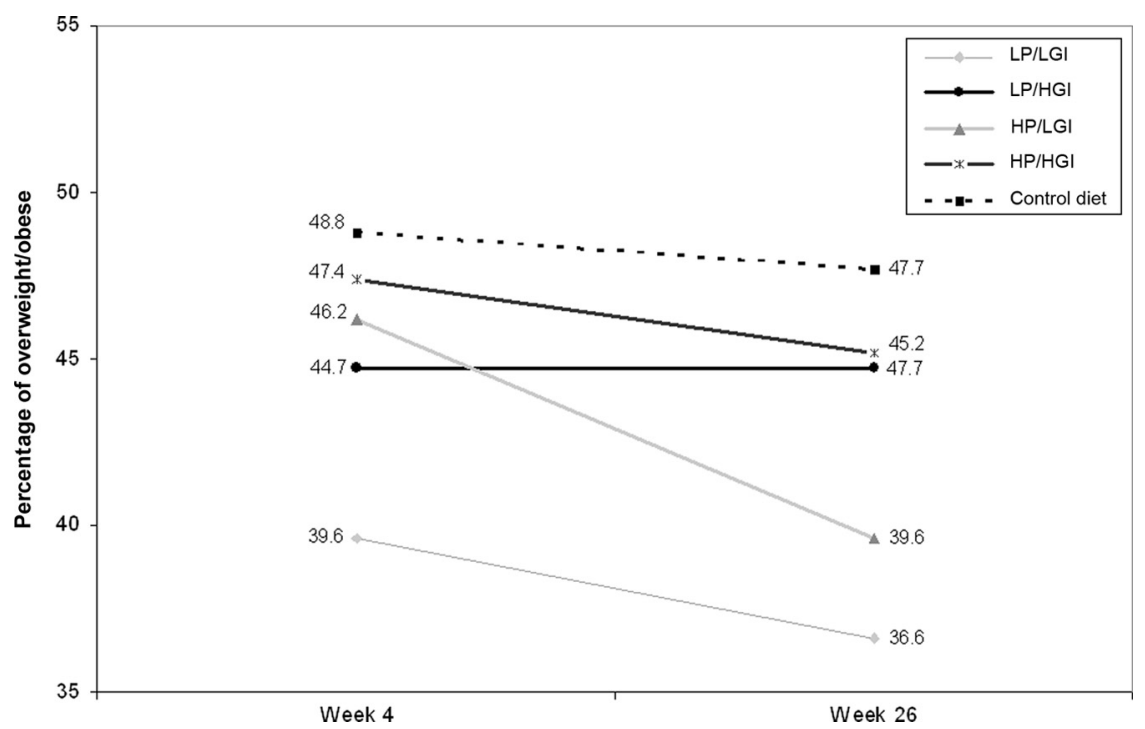

FIGURE 4

Changes in the proportion of overweight and obese children over the 6-month dietary intervention. Levels of significance were assessed by using McNemar test. ${ }^{a} P=.031$ for the HP/LGl group.

than-intended protein intake difference between the HP and LP groups. ${ }^{11,12}$

It has been suggested that LGI diets are inversely associated with overweight when compared with $\mathrm{HGl}$ diets. ${ }^{13,14,16,29,31}$ The majority of earlier studies have demonstrated this protective effect of LGI diets in children by assessing the short-term effects of LGI meals. ${ }^{13,16,32}$ Although our intervention was not focused on weight loss, making comparisons with earlier studies problematic, the present study showed that Gl did not affect body weight in children, thereby calling into question the long-term potential of such diets on weight control. However, our intervention was not successful in achieving the recommended 15-point $\mathrm{Gl}$ difference between the $\mathrm{LGl}$ and $\mathrm{HGl}$ groups because the self-reported difference was $2.3 \mathrm{GI}$ U. LGI diets, when compared with $\mathrm{HGl}$ diets, have also been found to decrease fat mass and increase lean body mass in adults. ${ }^{33}$ The present study did not show any beneficial impact of the LGI diet compared with the HGI diet on children's body composition. The outcome in the LGI and HGI groups was within the normal range of variation, contradicting an earlier study in which the impact of $\mathrm{LGl}$ and $\mathrm{HGl}$ meals on body weight among children was compared. ${ }^{34}$

Results from the current study are not directly comparable to earlier reports. In contrast with earlier studies, $11,2,35$ the current intervention did not give emphasis on weight loss, but examined how appetite regulation would affect body weight. In addition, the inclusion of normal-weight children in our sample did not allow for advice on weight loss to be provided to children. Nevertheless, it is promising that this intervention produced favorable changes in some anthropometric measurements in the overall sample of children. The DiOGenes study is also the first dietary study in which the effect of both protein and Gl content in children from different countries is examined. ${ }^{9}$

Although children were not always present at the randomization visit when their prescribed diet would be explained to them, research has indicated that parents are able to lower the Gl of their child's diet after a description of the LGI diet. ${ }^{36}$ However, the high dropout rate limits the external validity of our findings. This level of attrition approximates an earlier intervention study ${ }^{35}$ but is higher compared with studies in which diets with varying protein content in children were examined. ${ }^{11,12}$ Because both of these earlier studies were conducted in controlled settings, the high dropout rate in our sample may reflect the difficulties participants confront when trying to change their diet in real-life settings. Perhaps the high dropout rate also resulted in the lower-thanexpected observed effect size of $72 \%$. 
However, children's participation was completely dependent on their parents; thus, a child would withdraw if their parents withdrew their participation. Indeed, the fact that children randomly assigned to the LP/HGI group were more likely to withdraw from the study or not attend all examinations is consistent with what was reported in the $\mathrm{LP} / \mathrm{HGl}$ adult participants of the DiOGenes study, who also gained the highest amount of body weight and had the lowest decrease of fat mass during the intervention compared with the other dietary groups. ${ }^{9}$ Also, children might have enrolled at the insistence of their parents, which may have resulted in varying degrees of motivation to comply with study requirements. This might have led to the low compliance with the dietary record completion. Future intervention studies should address the need for active involvement of children to increase their effectiveness.

\section{REFERENCES}

1. Freedman DS, Dietz WH, Srinivasan SR, Berenson $\mathrm{G}$. The relation of overweight to cardiovascular risk factors among children and adolescents: the Bogalusa Heart Study. Pediatrics. 1999;103(6 pt 1): 1175-1182

2. Must A, Strauss RS. Risks and consequences of childhood and adolescent obesity. Int J Obes Relat Metab Disord. 1999; 23(suppl 2):S2-S11

3. Deckelbaum RJ, Williams CL. Childhood obesity: the health issue. Obes Res. 2001; 9(suppl 4):239S-243S

4. Ebbeling CB, Pawlak DB, Ludwig DS. Childhood obesity: public-health crisis, common sense cure. Lancet. 2002;360(9331): 473-482

5. Dietz WH. Childhood weight affects adult morbidity and mortality. J Nutr. 1998; 128(suppl 2):411S-414S

6. Casswall TH. Should a diet containing high protein and high glycemic load be blamed for the epidemic of overweight and obese children? J Pediatr Gastroenterol Nutr. 2007;45(1):19-21

7. Reilly JJ. Childhood obesity: an overview. Child Soc. 2007;21(5):390-396

8. Due A, Toubro S, Skov AR, Astrup A. Effect of
Finally, we used 3-day dietary records to determine dietary changes, which are considered valid instruments for children. ${ }^{37}$ However, we cannot rule out that parents might not have accurately recorded what their child consumed ${ }^{36}$ In addition, underreporting of energy intake might possibly have occurred, although the estimation of changes in intakes over time and the fact that participants act as their own controls when assessing dietary intake repeatedly may partially control for this. Moreover, we did not aim to detect differences in energy intake between the groups but rather used dietary assessment to estimate the relative macronutrient composition and $\mathrm{Gl}$ of the diets before and after the intervention.

\section{CONCLUSIONS}

The results of this study show that neither Gl nor protein had an isolated effect on body composition

normal-fat diets, either medium or high in protein, on body weight in overweight subjects: a randomised 1-year trial. Int $J$ Obes Relat Metab Disord. 2004;28(10): 1283-1290

9. Larsen TM, Dalskov S, van Baak M, et al. The Diet, Obesity and Genes (DiOGenes) dietary study in eight European countries: a comprehensive design for long-term intervention. Obes Rev. 2010; 11(1):76-91

10. Paddon-Jones D, Westman E, Mattes RD, Wolfe RR, Astrup A, Westerterp-Plantenga M. Protein, weight management, and satiety. Am J Clin Nutr. 2008;87 (5):1558S-1561S

11. Gately PJ, King NA, Greatwood HC, et al. Does a high-protein diet improve weight loss in overweight and obese children? Obesity (Silver Spring). 2007;15(6): 1527-1534

12. Rolland-Cachera MF, Thibault H, Souberbielle JC, et al. Massive obesity in adolescents: dietary interventions and behaviours associated with weight regain at 2 y follow-up. Int J Obes Relat Metab Disord. 2004;28(4):514-519

13. Ludwig DS, Majzoub JA, Al-Zahrani A, Dallal GE, Blanco I, Roberts SB. High glycemic index foods, overeating, and obesity. Pediatrics. among this sample of children after an ad libitum diet, with emphasis on appetite regulation rather than weight loss. However, the LP/HGI combination increased body fat, whereas the HP/LGI combination was protective against obesity. The limitations of the study should be considered before effective dietary macronutrient composition to reduce childhood adiposity are established.

\section{ACKNOWLEDGMENTS}

The DiOGenes study was partially funded by the European Community (contract F00D-CT-2005-513946). Financial contributions from local sponsors were provided to the supermarket centers, which also received a number of foods free of charge from food manufacturers. A full list of these sponsors is available at www.diogenes-eu.org/ sponsors.

1999;103(3). Available at: www.pediatrics. org/cgi/content/full/103/3/e26

14. Brand-Miller JC, Holt SH, Pawlak DB, McMilIan J Glycemic index and obesity. Am J Clin Nutr. 2002;76(1):281S-285S

15. Flint A, Møller BK, Raben A, et al. The use of glycaemic index tables to predict glycaemic index of composite breakfast meals. $\mathrm{Br} J$ Nutr. 2004;91(6):979-980

16. Warren JM, Henry CJK, Simonite V. Low glycemic index breakfasts and reduced food intake in preadolescent children. Pediatrics. 2003;112(5). Available at: www. pediatrics.org/cgi/content/full/112/5/e414

17. Buyken AE, Trauner K, Gunther AL, Kroke A, Remer T. Breakfast glycemic index affects subsequent daily energy intake in freeliving healthy children. Am J Clin Nutr. 2007; 86(4):980-987

18. Saris WH, Harper A. DiOGenes: a multidisciplinary offensive focused on the obesity epidemic. Obes Rev. 2005;6(2):175-176

19. Moore CS, Lindroos AK, Kreutzer M, et al. Strategy to manipulate ad libitum macronutrient intake, and glycaemic index, across eight European countries in the Diogenes study. Obes Rev. 2010;11(1):67-75

20. Skov AR, Toubro S, Raben A, Astrup A. A 
method to achieve control of dietary macronutrient composition in ad libitum diets consumed by free-living subjects. Eur J Clin Nutr. 1997;51(10):667-672

21. Saris WHM, Astrup A, Prentice AM, et al. Randomized controlled trial of changes in dietary carbohydrate/fat ratio and simple vs complex carbohydrates on body weight and blood lipids: the CARMEN study. The Carbohydrate Ratio Management in European National diets. Int J Obes Relat Metab Disord. 2000;24(10):1310-1318

22. Institute of Medicine, Food and Nutrition Board. Dietary Reference Intakes for Energy, Carbohydrate, Fiber, Fat, Fatty Acids, Cholesterol, Protein and Amino Acids (Macronutrients). Washington DC: National Academy Press; 2002

23. Aston LM, Jackson D, Monsheimer S, et al. Developing a methodology for assigning glycaemic index values to foods consumed across Europe. Obes Rev. 2010;11(1):92-100

24. Cole TJ, Bellizzi MC, Flegal KM, Dietz WH. Establishing a standard definition for child overweight and obesity worldwide: international survey. BMJ. 2000;320(7244): $1240-1243$

25. Lachin JM. Statistical considerations in the intent-to-treat principle. Control Clin Trials. 2000;21(3):167-189

26. Graham JW, Olchowski AE, Gilreath TD. How many imputations are really needed? Some practical clarifications of multiple imputation theory. Prev Sci. 2007;8(3):206-213

27. Ludwig DS. The glycemic index: physiological mechanisms relating to obesity, diabetes, and cardiovascular disease. JAMA. 2002;287 (18):2414-2423

28. Pawlak DB, Ebbeling CB, Ludwig DS. Should obese patients be counselled to follow a low-glycaemic index diet? Yes. Obes Rev. 2002;3(4):235-243

29. Ludwig DS. Dietary glycemic index and obesity. J Nutr. 2000;130(suppl 2S):280S-283S

30. Hosking J, Metcalf BS, Jeffery AN, Voss LD, Wilkin TJ. Validation of foot-to-foot bioelectrical impedance analysis with dual-energy $x$-ray absorptiometry in the assessment of body composition in young children: the EarlyBird cohort. Br J Nutr. 2006;96(6): 1163-1168

31. McMillan-Price J, Brand-Miller J. Lowglycaemic index diets and body weight regulation. Int J Obes (Lond). 2006;30:S40-S46

32. Ball SD, Keller KR, Moyer-Mileur LJ, Ding YW,
Donaldson D, Jackson WD. Prolongation of satiety after low versus moderately high glycemic index meals in obese adolescents. Pediatrics. 2003;111(3):488-494

33. Bouché C, Rizkalla SW, Luo J, et al. Five-week, low-ǵlycemic index diet decreases total fat mass and improves plasma lipid profile in moderately overweight nondiabetic men. Diabetes Care. 2002;25(5):822-828

34. Henry CJK, Lightowler HJ, Strik CM. Effects of long-term intervention with low-and highglycaemic-index breakfasts on food intake in children aged 8-11 years. Br J Nutr. 2007; 98(3):636-640

35. Spieth LE, Harnish JD, Lenders CM, et al. A low-glycemic index diet in the treatment of pediatric obesity. Arch Pediatr Adolesc Med. 2000;154(9):947-951

36. Young PC, West SA, Ortiz K, Carlson J. A pilot study to determine the feasibility of the low glycemic index diet as a treatment for overweight children in primary care practice. Ambul Pediatr. 2004;4(1):28-33

37. Olsen IE, Mascarenhas MR, Stallings V. Clinical assessment of nutritional status. In: Walker WA, Watkins JB, Duggan C, eds. Nutrition in Pediatrics. 3rd ed. Hamilton, Ontario, Canada: BC Decker Inc; 2003:7-8 


\section{The Effect of Protein and Glycemic Index on Children's Body Composition: The DiOGenes Randomized Study}

Angeliki Papadaki, Manolis Linardakis, Thomas M. Larsen, Marleen A. van Baak, Anna Karin Lindroos, Andreas F. H. Pfeiffer, J. Alfredo Martinez, Teodora Handjieva-Darlenska, Marie Kunesová, Claus Holst, Arne Astrup, Wim H. M. Saris and Anthony Kafatos

Pediatrics 2010;126;e1143; originally published online October 11, 2010; DOI: $10.1542 /$ peds. 2009-3633

\section{Updated Information \& Services}

\section{References}

\section{Citations}

Subspecialty Collections

Permissions \& Licensing

Reprints including high resolution figures, can be found at: http://pediatrics.aappublications.org/content/126/5/e1143.full. html

This article cites 33 articles, 7 of which can be accessed free at:

http://pediatrics.aappublications.org/content/126/5/e1143.full. html\#ref-list-1

This article has been cited by 4 HighWire-hosted articles: http://pediatrics.aappublications.org/content/126/5/e1143.full. html\#related-urls

This article, along with others on similar topics, appears in the following collection(s):

Nutrition \& Metabolism

http://pediatrics.aappublications.org/cgi/collection/nutrition_a nd_metabolism

Information about reproducing this article in parts (figures, tables) or in its entirety can be found online at: http://pediatrics.aappublications.org/site/misc/Permissions.xht $\mathrm{ml}$

Information about ordering reprints can be found online: http://pediatrics.aappublications.org/site/misc/reprints.xhtml

PEDIATRICS is the official journal of the American Academy of Pediatrics. A monthly publication, it has been published continuously since 1948. PEDIATRICS is owned, published, and trademarked by the American Academy of Pediatrics, 141 Northwest Point Boulevard, Elk Grove Village, Illinois, 60007. Copyright @ 2010 by the American Academy of Pediatrics. All rights reserved. Print ISSN: 0031-4005. Online ISSN: 1098-4275.

\section{American Academy of Pediatrics}

